\title{
Die charakteristische Ausflockung kolloidalen Goldes durch den Liquor progressiver Paralytiker.
}

\author{
Von
}

Dr. D. M. Kaplan,

Laboratoriumsdirektor des Neurologischen Instituts, Serologe am Monteflore Hospital, New York.

(Eingegangen am 12. Juli 1914.)

Die vollständige Ausflockung des kolloidalen Goldes in den höheren Konzentrationen des Liquor cerebrospinalis - unter Bildung einer treppenartigen Kurve - ist charakteristisch für allgemeine progressive Paralyse. Ich betone dies hier am Anfang wie am Ende meiner Arbeit, denn es stellt die Quintessenz meiner Untersuchungen dar. Neben der Tatsache, daß die beigefügten Tabellen für sich selbst sprechen und zeigen, wie spezifisch die Probe ist, soll diese Arbeit auch einige technische Beobachtungen bringen, auf die vorher weder von La nge, noch von anderen, die mit der Methode arbeiteten, aufmerksam gemacht worden ist, die ich aber für wesentlich halte zum erfolgreichen Ausfall der Reaktion.

Das Krankenmaterial, das den Untersuchungen diente, ist in zwei Hauptgruppen eingeteilt:

Gruppe 1. Patienten, die überhaupt syphilitisch infiziert wurden.

Gruppe 2. Luesfreie Patienten.

Gruppe 1 zerfällt in $\mathrm{A}$ und $\mathrm{B}$.

A. Patienten mit syphilitischer Lrkrankung des Nervensystems. (Tabelliert als „Neurale Lues".)

B. Syphilitiker mit intaktem Nervensystem. (Tabelliert als „Extraneurale Lues“.)

In Gruppe $1 \mathrm{~A}$ wurden 3 serologische Typen von Tabes, sowie Cerebrospinallues und allgemeine progressive Paralyse untersucht.

Die 3 Tabestypen sind:

1. Die gewöhnliche Tabes, die im Serum oder im Liquor Charakteristica der Syphilis zeigte, mit mehr oder weniger Reizerscheinungen (Pleocytose).

2. Die negative Tabes, die bei klinisch sicherer Diagnose serologisch keine Veränderungen aufwies.

3. „Wassermann-feste Tabes" und Taboparalyse. Letztere Diagnose klinisch sicher. 
D. M. Kaplan: Die charakteristische Ausflockung kolloidalen Goldes.

(4. Lues cerebrospinalis und

5. Progressive Paralyse, beide Diagnosen aus dem klinischen Befunde gestellt.)

\section{Überblick über die Tabellen. ${ }^{1}$ )}

1. Gewöhnliche Tabes dorsalis: 85 Fälle.

$\begin{array}{ll}\text { Serum Wassermann } & + \text { in } 47 \text { Fällen }=56,5 \% \\ \text { Liquor Wassermann } & + \text { in } 24 \text { Fällen }=28,2 \% \\ \text { Globulinüberschuß } & + \text { in } 20 \text { Fällen }=23,5 \% \\ \text { Pleocytose } & + \text { in } 84 \text { Fällen }=98,8 \%\end{array}$

(Fälle mit über 80 Zellen im Kubikmillimeter habe ich „hyperlymphocytäe Tabes" genannt. Dieser Typus fand sich in 10 Fällen $=11,8 \%$.)

Goldkurve.

00000000 in 41 Fällen
11000000 in 15 Fällen
22000000 in 14 Fällen
33200000 in 11 Fällen
45330000 in 1 Fall
34420000 in 1 Fall
13430000 in 1 Fall
14431000 in 1 Fall

2. Negative Tabes: 19 Fälle.

Wie erwähnt negativer serologischer Befund. Die höchste Anzahl Zellen war 11.

Gold k urve.
00000000 in 13 Fällen
11000000 in 1 Fall
30000000 in 1 Fall
22211000 in 2 Fällen
02022332 in 1 Fall
02211000 in 1 Fall

3. „Wassermann-feste Tabes“ und Taboparalyse: 21 Fälle.

Serum Wassermann + in 20 Fällen

Liquor Wassermann + in 19 Fällen

Globulinüberschuß $\quad+$ in 14 Fällen

Pleocytose über 12 Zellen pro $\mathrm{cmm}$ in 20 Fällen

über 80 Zellen pro $\mathrm{cmm}$ in 3 Fällen

Goldkurve.

$\begin{array}{cll}\text {,Wassermann-feste Tabes": } & 00000000 & 1 \text { Fall } \\ \text { (5 Fälle) } & 33110000 & 2 \text { Fälle } \\ \text { (ohne paralyt. Symptome) } & 22000000 & 1 \text { Fall } \\ & 55330000 & 1 \text { Fall }\end{array}$

1) Um die Arbeit nicht zu umfangreich zu gestalten, verzichten wir auf volle Wiedergabe der Tabellen. 


$\begin{array}{llrl}\text { Tabo-Paralyse: (16 Fälle) } & 44300000 & 3 \text { Fälle } \\ & 55543000 & 12 \text { Fälle } \\ & 50000000 & 1 \text { Fall }\end{array}$

Die Taboparalyse ist serologisch auch „Wassermann-fest“. Die Angabe der fehlenden oder vorhandenen paralytischen Symptome bezieht sich auf den klinischen Befund.

4. Progressive Paralyse: 52 Fälle.
Serum Wassermann + in 49 Fällen
Liquor Wassermann + in 47 Fällen
Globulinüberschuß $\quad+$ in 41 Fällen
Pleocytose $\quad+$ in 52 Fällen

(Die Lymphocytenzahl rangierte von 8-60 im Kubikmillimeter. In einem Fall fanden sich 63 und in einem anderen 80 pro Kubikmillimeter.)

Goldkurve.

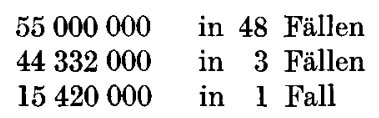

5. Lues cerebrospinalis: 50 Fälle.
Serum Wassermann
+ in 42 Fällen
Liquor Wassermann + in 34 Fällen
Globulinüberschuß + in 31 Fällen
Pleocytose
+ in 49 Fällen

Goldkurve.

00000000 in 22 Fällen
11000000 in 12 Fällen
22100000 in 7 Fällen
33210000 in 5 Fällen
44320000 in 2 Fällen
55541000 in 1 Fall (533 Zellen)
15520000 in 1 Fall (190 Zellen)

Gruppe 1 B: Extra-neurale Lues: 24 Fälle.

Serum Wassermann + in 19 Fällen

Liquor Wassermann + in 0 Fällen

Globulinüberschuß $\quad+$ in 0 Fällen

Pleocytose $\quad+$ in 0 Fällen

Goldkurve.

00000000 in 21 Fällen

11000000 in 2 Fällen

44200000 in 1 Fall $^{1}$ )

1) Kongenitale Lues. 
Gruppe 2: Luesfreie Patienten: 472 Fälle.

Rücken markstumoren . . . . 12 Fälle

(mit Globulinüberschuß, aber ohne Pleocytose)

Gold kurve: 00000000 in allen Fällen.

Multiple Sklerose . . . . . 18 Fälle

(serologisches Bild normal)

Goldkurve: 0000000017 Fälle

550000001 Fall

Epilepsie, Psychosen, Neurosen usw. 442 Fälle

Goldkurve: 00000000 in allen Fällen.

Bevor wir aus diesem Utberblick über die Tabellen unsere Schlußfolgerungen ziehen, sei die genaue Technik des Verfahrens und Erläuterungen, die „Goldkurve" betreffend, vorausgeschickt.

Besprechung verdienen:

\section{Technik.}

1. Chemikalien: Chemisch reines Kaliumcarbonat ist erforderlich, ferner Aurum chloratum purissimum (Merk) in 1-g-Glasampullen, Formaldehydlösung, wie sie im Handel ist und in pathologischen Laboratorien gebraucht wird, und schließlich reines Kochsalz.

2. Lösungen: Von Kaliumearbonat 2 proz.,

" Aurum chloratum 1 proz.,

, Formaldehyd $3 / 4$ proz. (Lange braucht eine 1 proz. Lösung),

", von Natriumchlorid 10 proz.

Sämtliche Lösungen werden mit doppeltdestilliertem Wasser hergestellt und sind haltbar.

3. Glasutensilien: Man halte einige Gros Reagensgläser (z. B. Gu uderlachs) bereit, ungefähr $12 \mathrm{~cm}$ lang und von $1,5 \mathrm{~cm}$ Durchmesser. Dieselben werden in destilliertem Wasser gereinigt, sterilisiert und vor dem Gebrauch 24 Stunden lang in einem großen Gefäß, in doppeltdestilliertem Wasser gehalten. Ferner sind nötig: ca. 1/2 Dtzd. Stehkolben von 11 Inhalt aus bestem Jenaer Glas. Manche Kolben zeigen nach dem Gebrauch einen Goldniederschlag am Glase. Wenn man solche Kolben mit Königswasser reinigt, der Goldniederschlag aber nach dem nächsten Gebrauch wieder auftritt - also vermutlich ein Glasdefekt vorhanden ist - dann darf der betreffende Kolben nicht mehr benutzt werden. Weder zum Verschluß dieser Kolben noch bei der Herstellung des destillierten Wassers oder der Chemikalien dürfen je Gummistopfen oder Gummiverbindungen gebraucht werden.

Schließlich sind erforderlich: 1 Dtzd. Pipetten mit 1 ccm Inhalt, 
eingeteilt in $1 / 10 \mathrm{ccm}$, sowie $1 / 2$ Dtzd. Pipetten von $10 \mathrm{ccm}$ Inhalt, in $1 \mathrm{ccm}$ graduiert.

4. Die Herstellung des kolloidalen Goldes verlangt viel Aufmerksamkeit. Das zum Gebrauch doppelt destillierte Wasser soll nicht auf Vorrat hergestellt werden, sondern man destilliert am besten das einmal destillierte Wasser gleich in den Literstehkolben hinein, und zwar $500 \mathrm{ccm}$ davon. Der Kolben soll eine entsprechende Marke aufweisen. Danach füge man $5 \mathrm{ccm}$ der 2 proz. Kaliumcarbonatlösung zu und erwärme 1/2 Minute über einem Doppelbunsenbrenner. Jetzt werden $5 \mathrm{ccm}$ der l proz. Goldlösung zugefügt und die Mischung weiter erhitzt, bis sie gerade anfängt zu kochen. Sowie die ersten Blasen erscheinen, wird der Kolben von der Flamme entfernt und sofort, aber langsam, $5 \mathrm{ccm}$ der 0,75 proz. Formaldehydlösung zugegossen, und zwar unter fortwährenden rotierenden Schüttelbewegungen. In wenigen Minuten nimmt die wasserklare Lösung dabei allmählich eine portweinrote Farbe an. Bei auffallendem Licht dürfen sich auch nicht die kleinsten Spuren von Gelb und Braun zeigen ${ }^{\mathbf{1}}$ ). Ferner soll eine gute Lösung absolut klar und durchsichtig sein, so daß man dahintergehaltenen gewöhnlichen Zeitungsdruck lesen kann. Wenn diese Bedingungen nicht erfüllt sind, wird man fehlerhafte Resultate erhalten.

Es ist vorteilhaft, nach dem Gebrauch in dem Kolben ca. $100 \mathrm{ccm}$ Königswasser zu halten, damit alle Spuren etwa anhaftenden Goldes gelöst werden. Wie schon erwähnt, sollte man Kolben, aus denen nicht alles Gold entfernt werden kann, nicht mehr benutzen.

\section{Ausführung der Probe.}

Man bereite sich eine 4 proz. Kochsalzlösung, indem man $4 \mathrm{ccm}$ der 10 proz. NaCl-Lösung zu $96 \mathrm{ccm}$ Wasser gibt. Dann stelle man 10-12 Reagensgläser auf und fülle in das erste Glas 1,8 ccm dieser Lösung in die übrigen je $1 \mathrm{ccm}$. Man gebe dann in das erste Glas $0,2 \mathrm{ccm}$ des zu untersuchenden Liquors und schüttele gut durch. Aus diesem pipettiere man $1 \mathrm{ccm}$ ab und gebe es in Glas $\mathrm{Nr}$. 2; schüttele wieder und gebe wieder $1 \mathrm{ccm}$ davon in Glas Nr. 3 usw, bis alle 10 bis 12 Gläser je $1 \mathrm{ccm}$ einer immer weniger konzentrierten Lösung enthalten. Der letzte Kubikzentimeter aus Glas 12 bleibt unbenutzt. Man erhält auf diese Weise in:

Glas Nr. 1 eine Verdünnung von $1: 10$

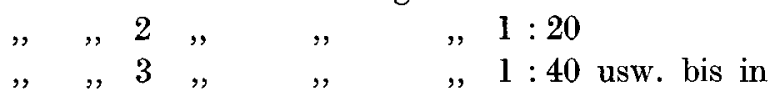

1) Man kann sich vergleichshalber diese Farbe durch Mischung folgender anderer Chemikalien herstellen: $15 \mathrm{ccm}{ }^{1} / 10 \mathrm{n}-\mathrm{NaOH}$-Lösung, $0,2 \mathrm{com}$ Ko ng or ot (0,5 proz. alkoholische Lösung), $0,3 \mathrm{~cm}$ Alizari n ( 1,0 proz. alkoholische Lösung). 
Glas Nr. 10 eine Verdünnung von $1: 5120$ oder in , , 12 ", , $1: 20480$.

Der Liquor cerebrospinalis soll frisch und frei von Blutbeimengungen sein. Jedes Reagensglas erhält nun einen Zusatz von $5 \mathrm{ccm}$ der KolloidalGoldlösung, wobei zu beachten ist, daß jedes einzelne sofort nach dem Zusatz gründlich geschüttelt werden muß. Die Resultate werden 24 Stunden später abgelesen. Vollkommene Fällung des kolloidalen Goldes zeigt sich in gänzlicher Entfärbung der Lösung. Sie ist dann wasserklar und wird durch $\mathrm{Nr}$. ,5" bezeichnet. Wo keinerlei Ausflockung erfolgte, bleibt die Farbe portweinrot, wie die übriggebliebene Lösung im Stehkolben. Dieser Zustand ist durch „, $0^{\circ}$ ausgedrückt. Zwischen 5 und 0 liegen etwa die Farbennuancen: wasserblau $=4$, hellblau $=3$, violett $=2$, stahlblau $=1$. Um ein Beispiel zu geben:

Wenn ein Fall für Paralyse spricht, wird in der Mehrzahl der Fälle in den ersten - sagen wir - 3 Reagensgläsern eine vollständige Ausfällung des kolloidalen Goldes erfolgen, eine fast vollständige in vielleicht den nächsten zwei und keine Farbenänderung in den letzten Gläsern. Ich gebe dies schematisch durch folgende Kurve wieder: 5554400000 , oder graphisch:

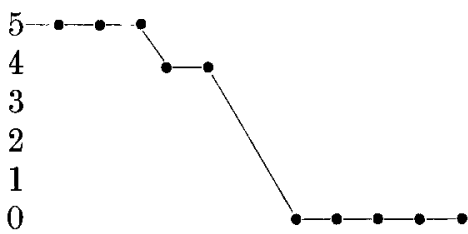

Nach dem Material, das mir zur Verfügung stand, ist die charakteristische „Treppenkurve" bei nichtluetischen Patienten und in Fällen von ,extraneuraler" Lues so selten, daß man wohl sagen kann, sie kommt praktisch nicht vor. In unseren Tabellen fand sie sich einmal bei multipler Sklerose und in einem Falle von kongenitaler Lues; in letzterem war die Ausflockung nicht einmal vollständig.

Bei Betrachtung der „neuralen Lues" finden wir unter Cerebrospinalsyphilis vier positive Kurven, aber nur eine "Treppenkurve“ mit kompletter Ausflockung; in diesem Fall waren 533 Zellen im Kubikmillimeter vorhanden, ein Befund, der schon an sich gegen Paralyse spricht.

Bei „Wassermannfester Tabes" ohne klinisch nachweisbare paralytische Symptome ergab sich nur ein einziges Mal die typische „Treppenkurve", dagegen waren bei Taboparalyse alle Kurven positiv, die meisten durchaus typisch "treppenartig", wobei bemerkt sei, daß eine Stufe (z. B. 550000000 ) auch schon eine „Treppe“ darstellt. 
Wir kommen nun zur progressiven Paralyse. Die Tabelle spricht für sich selbst. Wo wir hier - wie übrigens auch bei Taboparalyse keine ganz typische Kurve erhielten, handelte es sich um Fälle, die eine sehr energische Therapie durchgemacht hatten. Im übrigen fand sich die typische Kurve in $92,3 \%$ (48 von 52 Fällen).

Dieser Prozentsatz und der Charakter der Ausnahmen geben damit wohl eine hinreichende Stütze für den ersten Satz dieser Arbeit: die vollständige Ausflockung des kolloidalen Goldes in den höheren Konzentrationen des Liquor cerebrospinalis - unter Bildung einer treppenartigen Kurve - ist charakteristisch für allge meine progressive Paralyse. 